Research Article

\title{
Quality Engineering Tools Implementation a Comparison of Indian and Pakistani Business Organizations
}

\author{
Imran Ahmad Rana*, Muhammad Ali Yab and Ch. Abdul Rehman
}

Superior University, Lahore, Pakistan

Abstract: A quantitative study was conducted with an objective to compare Quality Engineering (Six
Sigma-SS) implementation practices at business organizations operating in South Asia (India and Pakistan)
and highlight such dimensions which contribute to the success. Instrument used for survey was built on
quality engineering and management system elements. Study has yielded key outcomes which highlight
that social dimension in use to practice SS in both of countries like behaviors and quality roles were varied.
Moreover, results obtained from regression analysis display that there are also differences between the
critical success factors (CSFs) of six sigma implementation in Indian and Pakistani organizations. Elements
like management commitment and six sigma deployment strategies were found significant in explaining
variability of six sigma results in the region. Results show that the countries were found similar on effect
of six sigma practices on customer satisfaction, where common elements like SS Training management,
Information and Communication planning and execution, and quality control practices found statistically
significant variables explaining variability of customer satisfaction. The study may help leaders, engineers,
professionals working at Indian-Pakistan based organizations to know significant organizational behaviors
associated with successful quality engineering management tools implementations as well as how to motivate
employees on waste reduction and productivity enhancement projects. This may facilitate training managers
to better target advance quality programs for the countries by going through analysis of selected aspects and
recommendations for deploying and implementing DMAIC methodology.
Received: January 13, 2020; Accepted: May 23,2020; Published:June 19,2020
*Correspondence: Imran Ahmad Rana, Adjunct Faculty, Ph.D Scholar, Superior University, Lahore, Pakistan; Email: qsipak@hotmail.com
Citation: Rana, I.A., M.A. Yab and C.A. Rehman. 2020. Quality engineering tools implementation a comparison of Indian and Pakistani
business organizations. Journal of Engineering and Applied Sciences, 39(1):22-34.
DOI: http://dx.doi.org/10.17582/journal.jeas/39.1.22.34
Keywords: Six sigma, Deployment, Management practices, Sustainability

\section{Introduction}

$\mathrm{P}$ urpose of any business has always been to make healthy growth, create customers and meet the varied needs of its stakeholders while ensuring long term survival of entity. Several methods, tools, techniques and management system approaches are being deployed by professionals to accomplish above objectives (Kumar and Antony, 2011). Business scenarios are experiencing rapid changes due to varied market needs, demanding customers and technological breakthroughs. Organizations in manufacturing, healthcare or services sector are forced to be competitive while delighting customers faster than their competitors. Six Sigma has emerged as being panacea for above challenges. The tool has been deployed by all sectors government agencies, hospitals, military, banks, retailing and above all manufacturing. During the past few years six sigma and lean tools has earned the reputation to solve chronic business problems, eliminate waste, reduce cost and add to customers' value (Moosa et al., 2010). 
Six Sigma management methodology was developed to address intense global competitive requirements. Organizations like Motorolla, GE, Ford having global businesses and intense competitive environments were giving much importance to DMAIC methodology and various tools and techniques therein. The concept of six sigma was developed at Motorolla under Bob Galvin's CEO reign. Bill Smith is known as father of six sigma (Gupta, 2006). In 1985, Bill Smith worked on and compiled first six sigma internal research report which was also read by Bob Galvin. In this report Smith identified correlation among how well a product performed in market place and how much rework was occurred during the manufacturing process. Moreover, he found that products which are produced with less or no defects also performed best at customer end. This is known as first six sigma formal research report (Gupta, 2006).

Integrating quality engineering (Six Sigma) with ISO 9001 quality management system and business excellence models to expedite implementation and achieve good results is widely used by businesses (Pedro et al., 2013; Karthi et al., 2011). The relationship of ISO 9001 and business excellence models with quality engineering methodology is facilitating researchers to study the impact of advance management systems. After successfulimplementation ofISO 9000,Pakistani organizations have started working on business advance quality management and engineering tools supported by various agencies (Moosa et al., 2010). In India Rajiv Ghandhi National Quality Award, Deming Award are being successfully practiced so, this awareness has helped in this study.

Purpose of this study is twofold first to know the implementation status of six sigma practices in both the countries. Secondly, six sigma implementation practices will be compared in order to learn what factors make program successful and what may move entities towards failure. No study was found conducted on comparing quality engineering or six sigma practices across the sectors in two countries. Some recent studies on the six sigma (quality engineering) implementation status were conducted in the region by (Abid et al., 2020; Rejikumar et al., 2020). The studies were limited to specific sectors and were not comparing the advanced practices in both countries.

\section{Literature review}

Purpose of the study as described in the previous section is to know the six sigma implementation and sustainability mechanism in mid-size to large organizations in India and Pakistan. This was requiring to view the six sigma status in literature with a special focus on its relation with various quality management practices like management commitment, employee and supplier relations, customer satisfaction, training management, information management etc.

ISO has defined Quality management as a set of 'coordinated activities that direct and control an entity with regard to quality. In order to explain various methodologies, philosophies and phenomena, a generic term Quality Management is widely used. Span of quality management moves from simple tools and techniques like inspection, suggestion system and quality circles to advance tools and methodologies like Six Sigma, Lean and TPM. Kamran and Sajid (2010) has described managing quality is significant for the sustainability and success of a businesses.

Table 1-A: Six sigma research study categorization.

\begin{tabular}{|c|c|c|c|}
\hline Category & Intent & Work & Status \\
\hline 1 & Implementation of Six Sigma program & $\begin{array}{l}\text { (Blakeslee, 1999; Does et al., 2002; Elliott, } \\
\text { 2003; Goh, 2002; Hahn et al., 1999; Islam, } \\
\text { 2004; Rowlands, 2003) }\end{array}$ & $\begin{array}{l}\text { theoretical foundations not } \\
\text { available }\end{array}$ \\
\hline 2 & $\begin{array}{l}\text { Success of Six Sigma activities on } \\
\text { addressing management requirements }\end{array}$ & $\begin{array}{l}\text { Frank, 2003; Gale, 2003; Heuring, 2004; } \\
\text { Wyper et al., } 2000\end{array}$ & $\begin{array}{l}\text { theoretical analysis and } \\
\text { empirical analysis were missed }\end{array}$ \\
\hline 3 & $\begin{array}{l}\text { To investigate the successful } \\
\text { management practices for Six Sigma } \\
\text { management }\end{array}$ & $\begin{array}{l}\text { Antony et al., 2005; Coronado and Antony, } \\
\text { 2002; Devadasan et al., 2011; Kamran and } \\
\text { Sajid (2010) }\end{array}$ & $\begin{array}{l}\text { Theoretical factors begin to } \\
\text { emerge }\end{array}$ \\
\hline 4 & $\begin{array}{l}\text { Developing a theoretical framework and } \\
\text { verifies it empirically }\end{array}$ & $\begin{array}{l}\text { (Lee and Choi, 2006; Kamran and Sajid, } \\
\text { 2010; Kumar et al., 2011) }\end{array}$ & Introduced research framework \\
\hline 5 & Relation of Lean and Six sigma & $\begin{array}{l}\text { Teo, 2010; Karthi et al., 2011; Pedro et al., } \\
\text { 2013; Qun-Zhang et al., 2012) }\end{array}$ & Exploring \\
\hline
\end{tabular}

\begin{tabular}{l|l|l|l}
\hline June 2020 & Volume 39 & Issue 1 & Page 23
\end{tabular} 
While reviewing literature it was found that a number of studies have been conducted during the past 15 years on the subject. These can be categorized into five major categories (Table 1A). First of all, research work was done on fundamental concept of how to implement the six sigma in companies. A number of papers have been written on this group and theoretical foundations are missing in the area. When we look onto second category, it is learnt this is addressing how the six sigma activities were successful in addressing certain management requirements and often both theoretical analysis and empirical analysis are omitted. The third category is to investigate the successful management practices of the six sigma management and some theoretical factors begin to emerge here. The fourth category is on developing a theoretical framework and verifies it empirically. The first three categories heavily rely on the descriptive analysis without relevant or clear research model. Therefore, the fourth category was introducing framework for research. Now the fifth category is going to be exploring where relation of Lean six sigma is studied with reference to high performance, innovation and cultural breakthroughs.

Marksberry and Parsley (2011) and Salvendy (2001) characterized industrial engineering as the branch of engineering that deals with design, development, deployment and improvement of integrated systems comprising on human resources, information and equipment that apply specialized skills, knowledge and behaviors in mathematical, physical and social sciences along with broad principles of engineering analysis. Whereas quality management is widely known as a complete management paradigm for improving overall company performance, effectiveness and competitiveness under industrial engineering discipline (Mellat et al., 2011). So, it can be inferred that industrial engineering may also be termed as quality engineering or quality management. As per Ebrahimi and Sadeghi (2013) key practices that fall under the quality engineering management are human resources, customer focus, strategic management and leadership, risk and resource management. In turn six sigma is an advanced management system or tool to reduce cost by systematically improving mentioned quality engineering practices (Kamran and Sajid, 2010)

Quality engineering (SS) professionals have been found adopting advanced quality tool rather first focusing on the implementation and sustainability of simple to use and understand quality techniques. Due to this reason implementation of advanced tools and techniques proves to be a bitter experience and tool is considered as useless in their settings (Ponzi and Koenig, 2002; Ramberg, 2000; Zhivago, 2007). This is also true for the region currently being studied where adoption of quality tools is required by customers or highly competitive market environment to sustain a business.

Importance of quality culture has been also widely recognized in TQM because a number of firms fail to achieve benefits as advance quality management tools like six sigma and business excellence require to manage an inside out change in the way businesses are being managed. (Rajamanoharan and Collier, 2006). Attitude and behavior of staff are also of key value being considered on successfully implementing advance quality programs in different regions (Moosa et al., 2010).

To meet the competitive goals of companies Six Sigma was a healthy addition to the quality management body of knowledge. (Zhang et al.,2009), as soon as six sigma methodology start practicing in organizations it was observed this has considerably added on to competitiveness of businesses (Aboelmaged, 2010). The tool turned out to be a key methodology to reduce variation in day to day activities and processes addressing continual and breakthrough improvements (Andersson et al., 2006). On this Huq (2006) is of the view that attitudinal change and skill set is required to effectively and efficiently at use all the tools of Six Sigma effectively, is required to reach at goal of 3.4 defects per million opportunities (DPMO).

According to O'Donnell-Young and Pilotto (2006) there are three themes in six sigma i.e. customer focus, data focus and process focus. Same themes are also described in eight quality management principles (ISO 9001:2015). Significance of these themes becomes more important when we discuss organizational competitiveness

Emergence of six sigma as a tool has led to many heated debates in quality spheres, literature, corporate magazines, papers and e-media, all have been found discussiong its pros and cons (Harry, 2012; Khurshid et al., 2010; Kumar et al., 2008). 
Theoretical framework

Comparative research is normally discussed in relation to three mechanisms i.e. culture free, convergence and culture specific modes (Haire et al., 1966; Hofstede, 1980). The six sigma comparison study was conducted utilizing a culture free dimension. This displays that based on ISO 9001:2015 and daily management systems models (DMBT) there is no difference between six sigma implementation practices in India and Pakistan.

Six sigma has been vastly used in business organizations but Kumar et al. (2008) described that Six Sigma is still in its infancy stage. So, authors couldn't find any valid, tested and verified six sigma theoretical frameworks that can use in this study. One quality management model developed by Rao et al. (1999) witnessed as the only framework which has been verified, and tested in an international context model. This was employed in the study to move further. The instrument developed with mentioned support was consisting on nine aspects of six sigma implementation in a quality management way:

Quality engineering/ six sigma leadership (SSL): This describes the important role of senior, middle and junior management on deploying SS across the company. Here the role of senior management is very vital to keep the work going (Gale, 2003; Heuring, 2004).

Information and communication analysis (ICA): Six Sigma process is actually realized through carefully managing the information, communicating requirements and status and promotion of the results. This also involves the availability of up to date information and policies for staff members to proceed further (Does et al., 2002). Information utilization, standardization and analysis are considered very important for the smooth flow and growth of SS (Breyfogle et al., 2001).

Quality engineering/ six sigma deployment strategy (SSDS): Deployment of any tool and technique requires the customized strategic planning. While planning strategically the focus should be on establishing foremost thinking as well as integrating current knowledge and experience of company on quality management tools and customer satisfaction (Wheeler, 1993). This will help set goals and to allocate resources in comparison with importance of projects.
Quality engineering/ six sigma training and development for HRs (SSTD): To sustain six sigma initiatives in an organization, there will be need of a shift from only project basis to every day work life. So, the SS training and staff development should be planned keeping in view application on daily basis. Employees needs to be engaged in six sigma project selection discussions.

Quality practices sustainability (QPS): This will be managing the sustainability of quality management practices across the company i.e. design, deployment, application and maintenance of quality activities on day to day basis (Kamran and Sajid, 2010).

Internal customer supplier agreement (SQM): Organizations depend on raw materials and semifinished goods to make and deliver final products. Quality of final products can't be assured without involving suppliers in quality net (Rana, 2009).

Quality engineering / six sigma business results (SSBR): Six sigma methodologies unite business management tools and techniques to produce high results. The program systematically displays how much improvement has been introduced by combining quality tools under SS umbrella (Carry et al., 2007; Kumar et al., 2008).

Customer satisfaction management (CSM): This will describe how the organization is getting feedback from internal and external customers as well as how to use six sigma to enhance customer satisfaction (Leo, 2008).

Social culture of firms (SCF): This explains how the businesses are managing their overall culture and social practices for a sustainable business (Darshak et al., 2012; Kamran, 2010; Pedro et al., 2013).

\section{Hypotheses}

According to the culture-free approach in comparative management study, differences in cultural practices do not affect the practice of six sigma and other quality practices in organizations. So, following hypotheses were developed:

H1: In Indian and Pakistan, there is no difference in SS leadership for SS deployment.

$\mathrm{H} 2$ : In Indian and Pakistan, there is no difference in information communication analysis for six sigma projects. 
H3: In both of countries, there is no difference in six sigma deployment strategy.

H4: In Indian and Pakistan, there is no difference in SS trainings and development for HRs.

H5: Quality management programs are equally sustainable in Indian and Pakistan.

H6: There is no difference in internal customer supplier quality relation between India and Pakistan.

H7: There is no difference in six sigma business results obtained from six sigma in India and Pakistan. H8: There is no difference in Customer Satisfaction management due to six sigma practices Mgt between Indian and Pakistan.

H9: There is no difference between social culture of firms implementing six sigma in both India and Pakistan.

\section{Materials and Methods}

\section{Study instrument}

It was also very important to decide the mode of inquiry (Creswell and Tashakkori, 2007). In this connection two approaches found widely used in quantitative perspective were experimental design and survey design. Survey design approach has the ability to describe all possible aspects of a given population in a quantitative way. Focusing on the ability of survey research in social sciences in special reference to total quality management and firm's performance (Sureshchandar et al., 2003; Gould, 2007) it was decided to use survey method to realize the purpose of current research. As the survey was requiring contacting large number of professionals in two geographically different regions, in the scenarios researcher are required to eliminate the element of bias. So, a questionnaire was developed which was sent to six sigma professionals by email.

Further, it was required to finalize the theoretical measures that encompass the six sigma practices. (Sekaran and Wagner,1980), as described in section 3 a theoretical framework was developed. Due to the well awareness of ISO 9000 standards and business respective excellence models (PMQA, RGNQA) concepts were utilized to develop the survey questionnaire. The survey instrument used by Mellat et al. (2006) for quality management study was used with some modifications due to regional settings. Then the modified instrument was validated, tested and verified based on internationally recognized framework. The instrument was comprised on nine constructs customized to six sigma practices under quality management umbrella. A five point likert scale was employed to measure the items. To further check and ensure reliability (for changes) of the face and content of the instrument a panel of five experts comprising on two practitioners, one $\mathrm{MBB}$, one academia and one survey expert was engaged. Changes recommended by the panelist were incorporated into the instrument. In this study, the values of Cronbach's alpha derived for the refined nine constructs ranged between 0.782 to 0.946 , indicating a high reliability of the scales. Construct reliability coefficients of 0.70 or more are considered good

Furthermore, to assess, do participants understand what is intend from questions five interviews of practitioners were conducted.

\section{Data management}

In this study Data was taken from the India and Pakistan companies to know the specific association between the six sigma practices in both of countries. These countries were chosen due to rising successful implementations of six sigma programs there, as suggested by many studies (Darshak et al., 2012; Nakhai and Neves, 2009; Kamran and Sajid, 2010; Qun et al., 2012). The study was based on the six sigma professionals trained and certified for SS program by TQMI -India and PIQC-Pakistan. It was known that approximately $80-90 \%$ of six sigma professionals' population was registered with TQMI-India and PIQC-Pakistan in their respective countries. So, the sample was highly representative of total six sigma population there. As the SS professionals were stratified in different regions of both the countries so a stratified random sampling method was utilized which was suitable in the scenario and data was representative of total population. Pilot study was also conducted through 19 practitioners majority working in manufacturing environment. Overall response rate on pilot studywas $53 \%$. Then questionnaire was emailed to 1350 professionals engaged in quality engineering (Six Sigma) programs at their organizations in both countries. 183 filled questionnaires were received, of those, 141 respondents qualified on fully responding all questions (around 70 professionals from each country). The results obtained from the study were analyzed using SPSS 20 software. The sample size is although low but Sullivan et al. (2017) clarified in their related study that technical comparative studies due to low maturation level in certain areas yield 
low response. They further discussed that sample size above 100 respondents for technical nature comparative studies can be termed as satisfactory.

\section{Results and Discussion}

The survey was based on ISO 9001:2015 and MBNQA 2011 (PMQA-Pak and RGNQA-India) foundations, six sigma study elements were assessed on a five-point Likert scale. Study Statistics present each grouped element, related mean as well as its standard deviation. It is noteworthy to mention here that for all study elements, the obtained values for reliability were more than 0.80 . For such type of study these values are acceptable as the minimum required limit is 0.70 (Rao et al., 1999).

Table 1 highlights the mean and standard deviation for each variable, upon measuring correlation between the variables, it was found that variables are significantly correlated at $\alpha=0.01$ (Ref. Table 2).

Table 1: Correlation matrix.

\begin{tabular}{|c|c|c|c|c|c|c|c|c|c|}
\hline & SS Led & ICA & SSDS & SSTD & QPS & SCM & SSBR & CSM & SCF \\
\hline \multicolumn{10}{|l|}{ SSL } \\
\hline Pearson Correlation & 1 & & & & & & & & \\
\hline Sig. (2-tailed) & - & & & & & & & & \\
\hline $\mathrm{N}$ & 141 & & & & & & & & \\
\hline \multicolumn{10}{|l|}{ ICA } \\
\hline Pearson Correlation & .684 & 1 & & & & & & & \\
\hline Sig. (2-tailed) & .001 & - & & & & & & & \\
\hline $\mathrm{N}$ & 141 & 141 & & & & & & & \\
\hline \multicolumn{10}{|l|}{ SSDS } \\
\hline Pearson Correlation & .782 & .657 & 1 & & & & & & \\
\hline Sig. (2-tailed) & .001 & .001 & - & & & & & & \\
\hline $\mathrm{N}$ & 141 & 141 & 141 & & & & & & \\
\hline \multicolumn{10}{|l|}{ SSTD } \\
\hline Pearson Correlation & .704 & .691 & .714 & 1 & & & & & \\
\hline Sig. (2-tailed) & .001 & .001 & .001 & - & & & & & \\
\hline $\mathrm{N}$ & 141 & 141 & 141 & 141 & & & & & \\
\hline \multicolumn{10}{|l|}{ QPS } \\
\hline Pearson Correlation & .728 & 714 & .665 & .611 & 1 & & & & \\
\hline Sig. (2-tailed) & .001 & .001 & .001 & .001 & - & & & & \\
\hline $\mathrm{N}$ & 141 & 141 & 141 & 141 & 141 & & & & \\
\hline \multicolumn{10}{|l|}{ SQM } \\
\hline Pearson Correlation & .796 & .674 & .593 & .682 & .578 & 1 & & & \\
\hline Sig. (2-tailed) & .001 & .001 & .001 & .001 & .001 & - & & & \\
\hline $\mathrm{N}$ & 141 & 141 & 141 & 141 & 141 & 141 & & & \\
\hline \multicolumn{10}{|l|}{ SSBR } \\
\hline Pearson Correlation & .717 & .659 & .637 & .682 & .728 & .768 & 1 & & \\
\hline Sig. (2-tailed) & .001 & .001 & .001 & .001 & .001 & .001 & - & & \\
\hline $\mathrm{N}$ & 141 & 141 & 141 & 141 & 141 & 141 & 141 & & \\
\hline \multicolumn{10}{|l|}{ CSM } \\
\hline Pearson Correlation & .742 & .664 & .697 & .751 & .716 & .766 & .781 & 1 & \\
\hline Sig. (2-tailed) & .001 & .001 & .001 & .001 & .001 & .001 & .001 & - & \\
\hline $\mathrm{N}$ & 141 & 141 & 141 & 141 & 141 & 141 & 141 & 141 & \\
\hline \multicolumn{10}{|l|}{ SCF } \\
\hline Pearson Correlation & .661 & .632 & .614 & .775 & .611 & .724 & .653 & .783 & 1 \\
\hline Sig. (2-tailed) & .001 & .001 & .001 & .001 & .001 & .001 & .001 & .001 & - \\
\hline $\mathrm{N}$ & 141 & 141 & 141 & 141 & 141 & 141 & 141 & 141 & 141 \\
\hline
\end{tabular}

All correlations are significant at the 0.01 level (2-tailed). 
Table 2: Group statistics.

\begin{tabular}{lllll}
\hline Group & $\mathbf{N}$ & Mean & Std. deviation & Std. error mean \\
\hline SSL & 73 & 3.42035 & 0.678754 & 0.73283 \\
& 68 & 2.57763 & 0.697415 & 0.41582 \\
ICA & 73 & 2.36916 & 0.712483 & 0.69553 \\
& 68 & 2.41224 & 0.635963 & 0.42316 \\
SSDS & 73 & 3.46245 & 0.607310 & 0.59769 \\
& 68 & 2.34170 & 0.658751 & 0.42597 \\
SSTD & 73 & 3.64931 & 0.705247 & 0.84176 \\
& 68 & 2.06327 & 0.769564 & 0.76978 \\
QPS & 73 & 3.64597 & 0.684716 & 0.70936 \\
& 68 & 3.41678 & 0.719562 & 0.56231 \\
SQM & 73 & 2.89745 & 0.736923 & 0.69864 \\
& 68 & 2.28133 & 0.709568 & 0.52581 \\
SSBR & 73 & 3.55498 & 0.892651 & 0.82750 \\
& 68 & 3.26501 & 0.715829 & 0.65856 \\
CSM & 73 & 2.91424 & 0.689441 & 0.70337 \\
& 68 & 2.63753 & 0.663062 & 0.48035 \\
SCF & 73 & 3.56812 & 0.670142 & 0.58714 \\
& 68 & 2.62451 & 0.659453 & 0.43968 \\
\hline
\end{tabular}

In order to find the similar pattern and difference between six sigma practices T-test was employed. Based on findings, it was assumed that both segments (India and Pakistan) are equal in variability. It was also tested at $\alpha=0.05$ level using the Levene's test.
Levene's test was employed since it is not sensitive to the sample distribution. $\mathrm{p}$-value were required to be greater than alpha 0.05 .

Result for Levene test for equality of variances are shown in Table 3. Here T-Test can't be used duet to its non-conformance to equality of variance assumption. So, Levene's tests which have inverse pairings (small sample size with high standard deviation and large sample size with low standard deviation) was employed. Apart from that other nonparametric tests or Welch t-test, or Welch or Brown-Forsythe (WBF) test served as alternative without making the assumption (Hinkle et al., 1994). In this scenario, variables of authors interest were social culture of firm (SCF), mature quality management programs (MQMP), and information, communication analysis (ICA). (The given variables have varied difference in variance so t-test cannot be used here).

It is worth mentioning here that Welch or BrownForsythe tests are also not taking into account equality of variance assumption and helped authors compare the two group (India and Pakistan) means on listed dependent set of variables i.e. three constructs of six sigma management. Welch or Brown-Forsythe test for SCF, MQMP and ICA are given in Table 4.

Table 3: Test of equality of variances and means.

\begin{tabular}{|c|c|c|c|c|c|c|c|c|}
\hline \multirow[t]{2}{*}{ Variables } & & \multicolumn{2}{|c|}{$\begin{array}{l}\text { Levene's test for } \\
\text { equality of variances }\end{array}$} & \multicolumn{5}{|c|}{ t-test for equality of means } \\
\hline & & $\mathbf{F}$ & Sig. & $\mathbf{t}$ & Df & Sig. & Mean difference & Std. error difference \\
\hline \multirow[t]{2}{*}{ SSL QledQL } & Equal variances assumed & 2.137 & .134 & 1.616 & 139 & .079 & 1.5191 & .7683 \\
\hline & Equal variances not assumed & & & 1.532 & 136 & .131 & 1.5191 & .7865 \\
\hline \multirow[t]{2}{*}{ ICA } & Equal variances assumed & 3.547 & .0501 & -.654 & 139 & .549 & -.4985 & .7479 \\
\hline & Equal variances not assumed & & & -.632 & 137 & .565 & -.4985 & .5678 \\
\hline \multirow[t]{2}{*}{ SSDS } & Equal variances assumed & 1.532 & .234 & 1.237 & 139 & .232 & .8473 & .6736 \\
\hline & Equal variances not assumed & & & 1.185 & 135 & .254 & .8473 & .6953 \\
\hline \multirow[t]{2}{*}{ SSTD } & Equal variances assumed & 2.875 & .058 & -1.62 & 139 & .134 & -1.2614 & .9768 \\
\hline & Equal variances not assumed & & & -1.49 & 135 & .142 & -1.2614 & .9942 \\
\hline \multirow[t]{2}{*}{ QMP } & Equal variances assumed & 2.984 & .068 & .986 & 139 & .286 & .8131 & .8064 \\
\hline & Equal variances not assumed & & & .963 & 136 & .351 & .8131 & .7871 \\
\hline \multirow[t]{2}{*}{ SQM } & Equal variances assumed & 3.265 & .113 & -.457 & 139 & .706 & -.4152 & .74821 \\
\hline & Equal variances not assumed & & & -.448 & 138 & .706 & -.4152 & .83148 \\
\hline \multirow[t]{2}{*}{ SSBR } & Equal variances assumed & 9.78 & 0.003 & 1.098 & 139 & .233 & .9765 & 1.0155 \\
\hline & Equal variances not assumed & & & 1.046 & 136 & .258 & .9765 & 1.4827 \\
\hline \multirow[t]{2}{*}{ CSM } & Equal variances assumed & 3.287 & .062 & .326 & 139 & .735 & .4821 & 1.6502 \\
\hline & Equal variances not assumed & & & .298 & 138 & .764 & .4821 & 1.6923 \\
\hline \multirow[t]{2}{*}{$\mathrm{SCF}$} & Equal variances assumed & 6.261 & .032 & -3.014 & 139 & .025 & -1.8052 & .8384 \\
\hline & Equal variances not assumed & & & -3.002 & 138 & .046 & -1.8052 & .8879 \\
\hline
\end{tabular}


Table 4: Robust test of equality of means.

\begin{tabular}{llllll}
\hline & & Statistic & df1 & df2 & Sig. \\
\hline SCF & Welch & 6.135 & 1 & 139 & 0.031 \\
& Brown-Forsythe & 6.135 & 1 & 139 & 0.031 \\
QPS & Welch & 1.401 & 1 & 139 & 0.212 \\
& Brown-Forsythe & 1.401 & 1 & 139 & 0.212 \\
ICA & Welch & .364 & 1 & 139 & 0.518 \\
& Brown-Forsythe & .364 & 1 & 139 & 0.518 \\
\hline
\end{tabular}

Above given three variables violate the normality assumption so their means compared by way of Welch or Brown-Forsythe test. It was noted that there is significant difference on social culture of firms between the two countries so H9 is rejected. Meaning thereby that due to maturity level of quality engineering/ six sigma tools implementation the social culture of firms differs between the two countries.

Now, it was required to test the means of SSL, SSDS, SSTD, SQM, SSBR, CSM with t-test. Table 3 highlights, $\mathrm{F}$-values are not significant. Likewise, (at $\alpha=0.05) \mathrm{H} 1, \mathrm{H} 2, \mathrm{H} 3, \mathrm{H} 4, \mathrm{H} 5, \mathrm{H} 6, \mathrm{H} 7$, and $\mathrm{H} 8$ can't be rejected based on insufficient evidence.

\section{Regression analysis}

Abid et al., 2020; Qun et al., 2012; Darshak and Mulchand,2012; Mosa et al.,2010) have identified the critical success factors for six sigma implementation in India and Pakistan which have high impact on a firm performance. In this regard authors have determined six sigma business results and customer satisfaction as two dependent variables (outcome) of six sigma practices. The variables which were significant in highlighting variability across six sigma business results and customer satisfaction were known using Regression analysis (stepwise regression).

\section{Six sigma business results (SSBR)}

In Pakistan, the results of a stepwise regression showed that quality practices sustainability (QPS), social culture of firms (SCF), supplier quality management (SQM), and support for six sigma training and development (SSTD) explain more than 70 percent of the variability in quality results $\left(\mathrm{R}^{2}=0.75\right)$, which is very good predictability (see Table 5 ).

Using the same analysis, the results for India showed that supplier quality management (SQM), six sigma leadership (SSL), information and communication availability (ICA), and social culture of firms (SCF) account for more than 53 percent of variability in quality results $\mathrm{R}^{2}=0.59$ (see Table 6 ). Comparing the results of the two models, it was found that while there is a difference in the critical success factors between the India and Pakistan, supplier quality management and social culture of the firm emerged as the common variables in both countries influencing six sigma business results.

Table 5: Regression analysis on Business Results (Pakistan).

\begin{tabular}{|c|c|c|c|c|}
\hline Model & $\mathbf{R}$ & $\mathrm{R}$ square & $\begin{array}{l}\text { Adjusted R } \\
\text { square }\end{array}$ & $\begin{array}{l}\text { Std. error of the } \\
\text { estimate }\end{array}$ \\
\hline 1 & $.772^{\mathrm{a}}$ & .615 & .593 & 6.11432 \\
\hline 2 & $.813^{\mathrm{b}}$ & .665 & .661 & 5.65927 \\
\hline 3 & $.827^{c}$ & .676 & .672 & 5.21468 \\
\hline 4 & $.831^{\mathrm{d}}$ & .748 & .702 & 5.74842 \\
\hline
\end{tabular}

Table 6: Regression analysis on SS Business Results (India).

\begin{tabular}{lllll}
\hline Model & R & R square & $\begin{array}{l}\text { Adjusted R } \\
\text { square }\end{array}$ & $\begin{array}{l}\text { Std. error of the } \\
\text { estimate }\end{array}$ \\
\hline 1 & $.664^{\mathrm{a}}$ & .459 & .437 & 6.25428 \\
2 & $.726^{\mathrm{b}}$ & .496 & .492 & 5.74213 \\
3 & $.741^{\mathrm{c}}$ & .533 & .520 & 5.36720 \\
4 & $.754^{\mathrm{d}}$ & .586 & .548 & 5.00126 \\
\hline
\end{tabular}

${ }^{a}$ Predictors: (Constant), SQM; ${ }^{b}$ Predictors: (Constant), SQM, SSL; 'Predictors: (Constant), SQM, SSL, ICA; ${ }^{d}$ Predictors: (Constant), $S Q M, S S L, I C A, S C F$

The research pointed out QPS and SSTD as distinctive factors contributing to business results from implementation in Pakistan whereas SSL and ICA have been found distinctively contributing to organizational results from six sigma deployments in India.

\section{Customer satisfaction management (CSM)}

Companies consistently go on reducing cost, improve processes and enhance customer satisfaction as their six sigma practices got maturity (Breyfogle et al., 2004; Moosa et al., 2010). Harry and Schroeder (1999) are of the view that six sigma is a vital corporate effectiveness enhancement strategy being applied by companies to reduce inefficiencies and enhance customer satisfaction. To ensure success and high performance, six sigma methodology starts with firm wide deployment strategy then go through implementation sustainability and follow up by the June 2020 | Volume 39 | Issue 1 | Page 29 
key professionals. The effect of six sigma performance on customer satisfaction in Asia have been confirmed by many studies. is has been confirmed by various studies (Sujar et al., 2008)

Six Sigma has been known as the organizational change management, improvement and cost reduction mechanism (Teo, 2010). Stepwise regression method was applied to know the impact of six sigma practices on customer satisfaction.

In Table 7, outcome of regression analysis for Pakistan exhibits that social culture of firms (SCF), quality practices sustainability (QPS) and six sigma deployment strategies (SSDS) found among major predictors of customer satisfaction management which account for 81 percent of the variability in the customer satisfaction $(\mathrm{R} 2=0.811)$.

Table 7: Regression analysis on customer satisfaction Mgt (Pakistan).

\begin{tabular}{lllll}
\hline Model & R & R square & $\begin{array}{l}\text { Adjusted R } \\
\text { square }\end{array}$ & $\begin{array}{l}\text { Std. error of } \\
\text { the estimate }\end{array}$ \\
\hline 1 & $.846^{\mathrm{a}}$ & .707 & .704 & 7.51253 \\
2 & $.874^{\mathrm{b}}$ & .762 & .758 & 6.68452 \\
3 & $.874^{\mathrm{c}}$ & .811 & .801 & 6.24659 \\
\hline
\end{tabular}

aPredictors: (Constant), SCF; ${ }^{b}$ Predictors: (Constant), SCF, MQMP, 'Predictors: (Constant), SCF, MQMP, SSDS.

Whereas for India the results reveal the significant predictors of customer satisfaction as six sigma deployment strategies (SSDS), social culture of firm (SCF), quality practices sustainability (QPS) and supplier quality management (SQM). The model account for 74.5 percent of variability on customer satisfaction element, exhibiting a good predictability index (Ref. Table 8).

Table 8: Regression analysis on Customer Satisfaction Mgt(India).

\begin{tabular}{lllll}
\hline Model & R & R square $\begin{array}{c}\text { Adjusted R R } \\
\text { square }\end{array}$ & $\begin{array}{l}\text { Std. error of the } \\
\text { estimate }\end{array}$ \\
\hline 1 & $.741^{\mathrm{a}}$ & .552 & .543 & 8.22822 \\
2 & $.810^{\mathrm{b}}$ & .685 & .682 & 6.77912 \\
3 & $.839^{\mathrm{c}}$ & .720 & .714 & 6.24753 \\
4 & $.863^{\mathrm{d}}$ & .745 & .736 & 6.09361 \\
\hline
\end{tabular}

"Predictors: (Constant), SSDS; ${ }^{b}$ Predictors: (Constant), SSDS, SCF; 'Predictors: (Constant), SSDS, SCF, MQMP; ${ }^{d}$ Predictors: (Constant), SSDS, SCF, MQMP, SQM.
It has been found by the study that social culture of firm, mature quality management practices and six sigma deployment strategies (SSDS) in Indian and Pakistan have a major effect on customer satisfaction element.

Through the research results no difference found between major six sigma practices in surveyed Indian and Pakistani organizations' management system structure based on the ISO 9001:2015 and business excellence model criterion. This reiterates, the fact that SS practices under DMAIC are universal as well as are not associated with any context. The findings support generalizability of Six sigma practices. Tushar and Shrivastava (2008), Nakhai and Neves (2009), studied that Six Sigma practices are universally applicable by firms to improve responsiveness, reduce cost, improve profits and has major impact on quality management practices too. Above studies show clear generalizability of six sigma practices but authors of the study are not making any solid argument that six sigma practices are free of any context. Situations and scenarios may exist where these cannot be. Social differences may affect the practice of six sigma as revealed in study on significant difference in social culture of the firm exist between India and Pakistan. The argument can be confirmed through more research in multifaceted, cross cultural contexts.

Differences on SCF between India and Pakistan may be attached to six sigma tools awareness, SS base certifications, $\mathrm{T}$ and $\mathrm{D}$ cultures at firms in both of countries, where refining culture affects six sigma practices (Moosa et al., 2010). An in depth case study analysis will be required to know how social cultures of firm are different in India and Pakistan and they might be affecting six sigma practice.

Regression results also highlight regardless of differences made by six sigma practices in India and Pakistan Internal Customer Supplier Agreement (SQM) has been found to be a significant predictor of six sigma business results in these scenarios. This also supports the role of six sigma at supplier relation management like timely supplying products or delivering services to customers which exhibits how the supplier quality efforts can influence the improvements of the process through six sigma. (Darshak and Mulchand, 2012; Reosekar and Pohekar, 2013). So, initially deploying an internal daily management system to promote internal customer-

June 2020 | Volume 39 | Issue 1 | Page 30 
supplier (ICS) relations have been found expediting advanced tools implementation in south Asia (Ando and Kumar, 2013). Social culture of firms found to be a significant variable which is also common in contribution at both scenarios.

Effect of above two findings customer supplier quality management and social culture of the firm have been found statistically significant in describing variability to business results in both of the settings. This suggests the areas should be researched further to completely know the impact of other quality engineering programs on company's performance in both of these countries. This study should cover both of the aspects from ICS perspective in a company as well as its relations with outer world.

The authors' findings support the fact that the "soft side" of six sigma such as social culture of firm, social responsibility, community engagement and six sigma training and development are important predictors of six sigma business results in India and Pakistan. There is a vast evidence that six sigma programs if customized to internal settings provide competitive advantage to organizations (Sureshchandar et al., 2001; Darshak et al., 2012). The studies like ours clearly mention that these corporate competitive advantages cannot be ensured with core six sigma tools like statistical analysis, performance comparison but introducing such mix of cultural settings with technical capabilities and deployment strategies that can't be imitated by competition. The study exhibits these three advantages that can't be easily imitated and provide better corporate results. The finding may help training managers that customization of SS programs to specific work systems of an organization not only expedite implementation but also yields results.

While focusing on variability in customer satisfaction in India and Pakistan we found that social culture of firm, six sigma deployment strategies and mature quality management practices are statistically significant variables which account for variability here. This can be interpreted as in both of the countries there are similar conditions which affect customer satisfaction except one major difference which is significance of internal and external supplier quality awareness in India, which was ranked above Pakistan. This may be due to the fact that Indian companies due to multiple factors have kept internal external supplier customer relations at key position while improving organizational performance (Ando and Kumar, 2013)

While interpreting six sigma practices results in both countries authors can suggest some key points. At social culture of firms in these countries, professionals appreciate the actual differences in the social and management systems practices in both Indian and Pakistani organizations. If some Indian managed company is going to have business opportunity in Pakistan, here the social culture and human resource development structure in Pakistani organizations need to be known better. Accordingly, Pakistan organizations or organization from neighboring nations may have to provide significant importance to internal and external supplier relation management so as to tailor their management system accordingly.

\section{Conclusions and Recommendations}

Objectives of this study were to compare the business excellence cum quality management led six sigma implementation in India and Pakistan utilizing DMAIC, ISO 9001:2015 and regionally followed business excellence models as criterion. Social culture of firms while deploying six sigma in both of the countries was emerged as the key difference. This also highlights that social systems and organizational cultures in both countries are different to some extent which have their resultant impact on quality engineering tool e.g. six sigma.

The study has pointed towards vital characteristic of management system of organizations i.e. companies should work on developing such daily management system which are hard to imitate. This will be requiring incorporating behavioral way to manage six sigma implementations, key element here will be six sigma deployment strategies, six sigma training and development, information and communication sharing in firm's social context on a daily basis.

One of the study's limitations is the lower sample size from both of the countries due to the respondents' very low feedback. As the culture of research on advance quality engineering tools is still in its initial phase. Professionals working in the field or either too busy in their schedule where they can't respond or they might be hesitant even to respond anonymous queries. Further, the results of the study cannot be generalized to other regions, since the study was 
limited to the major cities of India and Pakistan which were considered alike.

The issue of multicolinearity was there in this study. The independent variables six sigma business results and customer satisfaction found correlated with each other. The correlation table shows that the independent variables are highly correlated. As the six sigma success is based on many inter related variables.

Future researchers interested on the topic are recommended to study another widely adopting discipline Lean, Six Sigma and QMS in this region or in other related Middle East, East Asian and AsiaEurope region. The studies will help easily generalize the results across the Asian region. When six sigma will be moving from its initial phases, the associated social aspect of DMAIC methodology will gain more attention. Recent trends toward six sigma or big data access, analysis, reporting and improvement could be considered as potential areas of research.

\section{Novelty Statement}

The paper has added to consider core social aspects in implementation of six sigma. Moreover, deploying internal daily management system to promote internal customer-supplier relations have been found expediting advanced tools implementation.

\section{Author's Contribution}

Imran Ahmad Rana: Contributed in drafting the manuscript, acquiring data, data analysis and subsequent revisions.

Muhammad Ali Yab: Supported in acquiring data, emailing questionnaire and initial review as per study requirements.

Ch. Abdul Rehman: Contributed in final review and approval of the paper.

\section{Conflict of interest}

The authors have declared no conflict of interest.

\section{References}

Aboelmaged, M.G., 2010. Six Sigma quality: A structured review and implications for future research. Int. J. Qual. Reliab. Manage., 27(3): 269-318. https://doi. org/10.1108/02656711011023294

Abid, M., O.M. Butt, Q. Ann, B. Rashid and N.S. Devi. 2020. Role of Critical Success Factors (CSF) in the implementation of six sigma in hospitals: A preliminary study in Pakistan. Asia-Pac. J. Hlth. Manage., 15(1): 5-13.

Andersson, R., H. Eriksson and H.K. Torstensson. 2006.Similarities and differences between TQM, six sigma and lean. TQM Mag., 18(3):282-296. https://doi.org/10.1108/09544780610660004

Ando, Y. and P. Kumar. 2013. Daily management the TQM way: The key to success in Tata Steel" $2^{\text {nd }}$ Ed. Prod. Qual. Publ. Pvt. India.

Antony,J.,M.Kumarand C.N.Madu.2005.Six sigma in small and medium-sized UK manufacturing enterprises: some empirical observations. Int. J. Qual. Reliab. Manage., 22(8): 860-874. https:// doi.org/10.1108/02656710510617265

Blakeslee, Jr, J.A., 1999. Implementing the six sigma solution. Qual. Prog., 32(7): 77.

Breyfogle, F.W., J.M. Cupello and B. Meadows. 2001. Managing six sigma: A practical guide to understanding, assessing, and implementing the strategy that yields bottom line success Wiley, New York.2001. 15: 272.

Carry, A., P. Gupta and C. Wilson. 2007. Six sigma deployment. Routledge.

Coronado, R.B., and J.Antony.2002. Critical success factors for the successful implementation of six sigma projects in organisations. The TQM magazine.

Creswell,J.W., and A.Tashakkori.2007.Developing publishable mixed methods manuscripts.

Darshak, A., Desai, J. Antony and M.B. Patel.2012. An assessment of the critical success factors for Six Sigma implementation in Indian industries. Int. J. Prod. Perform. Manag., 61(4): 426-444. https://doi.org/10.1108/17410401211212670

Does, R., E.v.d. Heuvel, J.d. Mast and S. Bisgaard. 2002. Comparing nonmanufacturing with traditional applications of six sigma. Qual. Eng. J., 15(1): 177-182. https://doi.org/10.1081/ QEN-120006720

Elliott, G., 2003. The race to six sigma; high quality standards take more than being in control. Ind. Eng., 35(10): 30-35.

Ebrahimi, M. and M. Sadeghi. 2013. Quality management and performance: An annotated review. Int. J. Prod. Res., 51(18): 5625-5643. https://doi.org/10.1080/00207543.2013.7934 26 
Frank, S., 2003. Applying six sigma to revenue and pricing management. J. Rev. Pricing Manag., 2(3): 245-254. https://doi.org/10.1057/ palgrave.rpm.5170071

Gale, S.F., 2003. Building frameworks for six Sigma success. Workforce, 82(5): 64-69.

Goh, T.N., 2002. A strategic assessment of Six Sigma. Qual. reliabil. eng. int., 18(5): 403-410.

Gould-Williams, J., 2007. HR practices, organizational climate and employee outcomes: Evaluating social exchange relationships in local government. Int.J.Hum. Resour. Manage., 18(9): 1627-1647.

Gupta, P., 2006. Six sigma business scorecard. McGraw Hill Professional.

Harry, M. and R. Schroeder. 1999. Six sigma: The breakthrough management strategy.

Haire, M., E.E. Ghiselli and L.W. Porter. 1966. Managerial thinking: An international study.

Hahn, G.J.,W.J.Hill,R.W.Hoerl and S.A.Zinkgraf. 1999. The impact of Six Sigma improvement, a glimpse into the future of statistics. Am. Stat., 53(3): 208-215.

Heuring,L.,2004. Six sigma in sight.HR Magazine, 49(3): 76-80.

Hinkle, D.E., W. Wiersma and S.G. Jurs. 1994. Applied statistics for the behavioral sciences, $3^{\text {rd }}$ edition. Boston: Houghton Mifflin.

Hofstede, G., 1980. Motivation, leadership, and organization: do American theories apply abroad? Organ. Dyn., 9(1): 42-63.

Huq, Z., 2006. Six sigma implementation through competency based perspective (CBP). J. Change Manag., 6(3): 277-289. https://doi. org/10.1080/14697010600941825

Islam, K.A., 2004. E-Learning: Gaining business value through six sigma, Chief Learning Officer, January, pp. 28-33.

Kamran, M. and A. Sajid. 2010. Critical analysis of six sigma implementation. Total Qual. Manag. Bus. Excell., 21(7): 2010. https://doi.org/10.10 80/14783363.2010.483100

Karthi, S., S.R. Devadasan and R. Murugesh. 2011. Lean six sigma through ISO 9001 standard-based quality management system: an investigation for research. Int. J. Prod. Qual. Manag., 8(2): 180-204. https://doi. org/10.1504/IJPQM.2011.041845

Kumar, M., J. Antony and M.K. Tiwari. 2011. Six sigma implementation framework for SMEs a roadmap to manage and sustain the change. Int.
J. Prod. Res., 49(18): 5449-5467. https://doi.or g/10.1080/00207543.2011.563836

Kumar, M., J. Antony, C.N. Madu, D.C. Montgomery and S.H. Park. 2008. Common myths of six sigma demystified. Int. J. Qual. Reliab. Manag., 25(8): 878-895. https://doi. org/10.1108/02656710810898658

Lee, K.C., and B. Choi. 2006. Six Sigma management activities and their influence on corporate competitiveness. Total Qual. Manage. Bus. Excell., 17(7): 893-911.

Leo, H.J., 2008. Optimization of the customer satisfaction by use of the Six-Sigma-Concepts from the view of an automotive subcontractor. Adv. Semin., 2008.

Marksberry, P. and D. Parsley. 2011. Managing the IE (Industrial Engineering) mindset: A quantitative investigation of Toyota's practical thinking shared among employees. J. Ind. Eng. Manag., 4(4): 771-799. https://doi. org/10.3926/jiem.293

Mellat, M., Parast, S.G. Adams, E.C. Jones, S.S. Rao and T.S. Raghu-Nathan. 2006. Comparing quality management practices between the United States and Mexico. Qual. Manage. J., 13(4): 36-49.

Mellat, M.P., E.C. Jones and S.G. Adams. 2011. Developing an instrument for measuring Six Sigma implementation. Int. J. Ser. Operat. Manage., 9(4): 429-452.

Moosa, K., A. Sajid, R.A. Khan and A. Mughal. 2010. An empirical study of TQM implementation: Examination of aspects versus impacts. Asian Bus. Manag., 9(4): 525-551. https://doi.org/10.1057/abm.2010.27

Nakhai, B. and J.S. Neves. 2009. The challenges of six sigma in improving service quality. Int. J. Qual. Reliab. Manage., 26(7): 663-684. https:// doi.org/10.1108/02656710910975741

Pedro, M., J. Requeijo, P. Saraiva and F. FrazãoGuerreiro. 2013. Integrating six sigma with ISO 9001. Int. J. Lean Six Sigma, 4(1): 36-59. https://doi.org/10.1108/20401461311310508

Ponzi, L.J. and M. Koenig. 2002. Knowledge management: Another management fad? Inf. Res., 8(1): 8.

Qun, Z., M. Irfan, M.A.O. Khattak, et al. 2012. Critical success factors for successful lean six sigma implementation in Pakistan. Interdisciplin. J. Contemp. Res. Bus., 4(1).

Rajamanoharan, I.D. and P. Collier. 2006. Six 
Sigma implementation, organizational change and the impact on performance measurement systems. Int. J. Six Sigma Competitive Advant., 2 (1): 48-68. https://doi.org/10.1504/ IJSSCA.2006.009369

Ramberg,J.S., 2000. Six Sigma: Fad or fundamental, Mike Richman, retrieved 5 December 2010,

Rana, I.A., 2009. Creating high performance organizations an Indo Pak Case. 2009. ANQ 2009 Tokyo conference proceedings. Paper A-12. http://anq2009.com

Rao, S.S., L.S. Solis and T.S. Raghu-Nathan. 1999. A framework for international quality management research: Development and validation of a research instrument. Total Qual. Manag., 10(7): 1047-1075. https://doi. org/10.1080/0954412997226

Rejikumar, G., A.A. Asokan and V.R. Sreedharan. 2020. Impact of data-driven decision-making in Lean Six Sigma: An empirical analysis. Total Qual. Manage. Bus. Excell., 31(3-4): 279-296.

Reosekar, R.S., and S.D. Pohekar. 2013. Design and development of Six Sigma implementation framework for Indian industries. Intl. J. Eng. Bus. Enterp. Appl, 5(2): 147-152.

Rowlands, H., 2003. Six sigma: A new philosophy or repackaging of old ideas? Eng. Manage., 13(2): 18-21.

Salvendy, G., 2001. Handbook of industrial engineering: Technology and operations management. New York: John Wiley and Sons, Inc.

Sekaran, U. and F.R. Wagner. 1980. Sense of competence: A cross-cultural analysis for managerial application. Group Organ. Stud., 5(3): 340-352.

Sujar, Y., P. Balachandran and N. Ramasamy. 2008. Six sigma and the level of quality characteristics, a study on indian software industries. AIMS Int. J. Manag., 2(1): 17-27.
Sullivan, J., M.E. Asmar,J. Chalhoub and H. Obeid. 2017. Two decades of performance comparisons for design-build, construction manager at risk, and design-bid-build: Quantitative analysis of the state of knowledge on project cost, schedule, and quality. J. Constr. Eng. Manag., 143(6): 04017009. https://doi.org/10.1061/(ASCE) CO.1943-7862.0001282

Sureshchandar, G.S., et al. 2001. A conceptual model for total quality management in service organizations. Total Qual.Manag., 12:343-363. https://doi.org/10.1080/09544120120034492

Sureshchandar, G.S., C. Rajendran and R.N. Anantharaman. 2003. The influence of total quality service age on quality and operational performance. Total Qual. Manage. Bus. Excell., 14(9): 1033-1052.

Teo, L.K., 2010. Critical success factors (CSFs) for lean six sigma (LSS) implementation and its impact on the performance of electronic manufacturing services (EMS) industries. Research Report Universiti Sains Malaysia.

Tushar, N.D. and R.L. Shrivastava. 2008. Six sigma, a new direction to quality and productivity management; WCECS 2008, October 22-24, 2008, San Francisco, USA.

Wheeler, D.J., 1993. Understanding variation, the key to managing chaos, SPC Press Knoxville, TN 1993.

Zhang, W., A.V. Hill and G.H. Gilbreath. 2009. Six sigma: A retrospective andprospective study, paper presented to POMS $20^{\text {th }}$ Annual Conference, Orlando, FL., 1-4 May, www. pomsmeetings.org/ConfPapers/011/0110254.pdf.

Zhivago, K., 2007. Why i hate management fads, Zhivago Management Partners, retrieved 22 June 2012, http://www.revenuejournal. com/2007/10/why_i_hate_management_fads.p hp. 